\title{
SITUACIÓN ACTUAL DE LOS ESTUDIOS SOBRE IBN MASARRA DE CÓRDOBA, PRECURSOR DE IBN fIARABĪ
}

\author{
PILAR GARRIDO CLEMENTE \\ Universidad de Salamanca
}

n este artículo, presentaré de manera breve el estado de la cuestión de
los estudios acerca de Ibn Masarra, analizando cómo ha sido tratado por las fuentes antiguas y cómo está siendo estudiado en la actualidad. Comenzaré con una introducción a algunos aspectos de su vida y su contexto para después abordar la situación del estudio de sus obras conocidas y terminaré dando un ejemplo textual de su trasmisión como antecesor de Ibn flArabī.

Veamos cómo se expresa Asín Palacios en su obra sobre el autor:

\begin{abstract}
El fenómeno de asimilación de la cultura oriental, que entre los musulmanes españoles se realizaba, no quebrantaba la ley eterna de la continuidad del pensamiento ibérico. Si los pensadores independientes iban a buscar, fuera de la patria, satisfacción a los anhelos ideales de su espíritu, era cabalmente porque en este espíritu circulaban todavía, por debajo de la superficie postiza y artificiosa de la religión nueva, los instintos, las tendencias, las aptitudes étnicas de un pueblo que, antes de someterse al Islam, había pensado y sentido otros dogmas, similares en el fondo, pero de un contenido emocional más rico y de un desarrollo filosófico más pleno. La intensa huella neoplatónica de la teología cristiana, las tradiciones neopitagóricas y gnósticas del priscilianismo, habían echado hondas raíces en las almas. Y esta psicología étnica, conservada tras el umbral de la conciencia es la que sobrevive y la que reanuda la vida del pensamiento español con los mismos caracteres de misticismo y de austeridad, en lo emocional, y de panteísmo naturalista, en lo especulativo ${ }^{1}$.
\end{abstract}

1 En este sentido, mostrando la misma tendencia "etnicista" que quiere "españolizar" a Ibn Masarra, afirma Asín al respecto: "Aunque la influencia predominante en la psicología étnica de la masa sería la cristiana, no son de despreciar ni la tradición priscilianista, que perduró dos siglos enteros, del IV al VI J. C., ni la neopitagórica de Moderato de Gades que, junto con la senequista, pueden explicar esa tendencia al idealismo místico y a la moral austera, como características de la 
En este trasfondo ideológico nacionalista que se define por sí sólo nos sitúa Asín Palacios a Ibn Masarra y su familia: "Síntoma de esta herencia psicológica es la raza de algunos de aquellos pensadores independientes, unidos con el parentesco legal de la clientela a familias árabes o berberiscas, pero en cuyas venas circulaba sangre española, como ocurre con el linaje del filósofo Ibn Masarra"2, a quien Asín considera "el más célebre entre los más antiguos de aquellos pensadores (siglo X)"3.

Reivindicar en nuestros días una "ley eterna de la continuidad del pensamiento ibérico" resultaría grotesco. Una cosa es explorar posibles influjos y herencias en un territorio, otra muy distinta "nacionalizar" el pensamiento vinculándolo a una raza y una sangre españolas. Hay que tener precaución con el tono de Asín, en especial en sus primeros trabajos. No obstante, a pesar de sus prejuicios, su ensayo sobre Ibn Masarra sigue siendo el principal referente de los estudios sobre el autor a través de las fuentes andalusíes, que Asín trata con notable rigor.

Comenzando un desarrollo biográfico del autor, comenta Asín:

De su padre flAbd Allāh aseguran sus biógrafos que era cliente de un berberisco de Fez o de uno de Jaén. [...] Los caracteres físicos de su padre confirman esta sospecha, pues por el color rubio de su pelo y el rojo vivo de su tez, pudo pasar a los ojos de los habitantes de Basora como siciliano, normando o de raza del norte, expuesto a ser vendido como esclavo ${ }^{4}$.

Sobre la familia de Ibn Masarra se conocen diferentes referencias que Asín Palacios ha ido recogiendo minuciosamente de las fuentes árabes, especialmente

\footnotetext{
raza. Con el gnosticismo maniqueo de Marco y Prisciliano son tan notables las analogías que presenta el sufismo de los masarríes, que podría tomarse a éstos como continuadores de los priscilianistas, de no constar positivamente el origen oriental de sus doctrinas. Sabido es que en la herejía de Prisciliano se habla de una materia primera universal, coeterna con Dios, se atribuye al alma un origen divino, se explica su unión con el cuerpo como castigo de un pecado, y su redención y retorno a la patria como efecto de la predicación de los profetas que enseñan a las almas una doctrina ascética con la cual se purifican: Finalmente se da a la letra de las Sagradas Escrituras una exégesis alegórica". Cf. Menéndez y Pelayo, Historia de los heterodoxos españoles, I, p. 98.

2 M., Asín Palacios, “Ibn Masarra y su escuela” en sus Obras escogidas, Madrid, 1946, p. 1.

${ }^{3}$ Idem.

4 Al-Farađī, b.(biografía) 650. Cf. ms. 100 de la Biblioteca de la Escuela de Estudios Árabes de Madrid de la obra de al-Farađī, que contiene la misma biografía del padre de Ibn Masarra.
} 
de biógrafos coetáneos e inmediatamente posteriores a nuestro autor que ofrecen rasgos de su vida en estilo hagiográfico.

Específicamente se refieren entre los miembros de su familia a su padre, flAbd Allāh, y a la comunicación que entre ambos tuvieron. Su padre flAbd Allāh viajó ya en su adolescencia desde su lugar de nacimiento, Córdoba, para visitar Oriente. Propone Asín Palacios que este viaje habría tenido lugar en el año 854 (240 H.), durante el emirato de Muhammad. "Era Basora, por aquellas fechas, uno de los focos literarios más espléndidos del mundo musulmán, y a las escuelas de sus famosos maestros acudían los españoles para formarse en las disciplinas filológicas y literarias" 5 . El padre de nuestro autor era un joven más que realizó su viaje por Oriente en busca de conocimiento, empapándose de las corrientes que circulaban en la época, en particular -según diversos autores- el mufltazilismo, tomando contacto con maestros espirituales y llevando a cabo también su viaje interior, su peregrinación. Al regresar a Córdoba -según documenta el padre Asín- entabló un estrecho vínculo de amistad con Jalīl al-Gafla ${ }^{6}$, quien habría sido su interlocutor más cercano. Tuvo además un círculo de discípulos ${ }^{7}$ con los que se comunicaba sobre asuntos literarios, teológicos y espirituales.

En el año 883 (269 H.) nació su hijo, Muhammad Ibn Masarra, al cual crió bajo una enseñanza espiritual y con quien desde su adolescencia compartió una vida de oración devota y sus inquietudes teológicas. Además de su padre, tenemos constancia de que también fueron sus maestros en ciencias tradicionales y hadiz en Córdoba Ibn Wađđāh y Muhammad b. flAbd al-Salām al-Jušanī 9 .

Relata también Asín que:

Apenas llegado el joven Muћammad a su mayoría de edad, y cuando todavía otros maestros podían torcer, con sus sugestiones, la dirección impresa por la educación paterna, vióse Ibn Masarra privado de la compañía de su padre que, agobiado de deudas, hubo de expatriarse voluntariamente para pasar en otros países, donde su ruina económica era ignorada, los últimos años de su vida. En manos de su hijo depositó, al marchar, todos sus libros para que con ellos completase su ilustración; y en La Meca, adonde se acogió, encontró la muerte en el año 899 (286 H.) ${ }^{10}$.

\footnotetext{
${ }^{5}$ M. Asín Palacios, op. cit., p. 40.

${ }^{6}$ Al-Farađī, p. 180. Sobre Jalīl al-Gafla, cf. Apéndice $2^{\circ}, \mathrm{n}^{\mathrm{o}} 4$.

7 Las biografías de los discípulos del padre de Ibn Masarra son las señaladas en la obra de Farađī con los $\mathrm{n}^{\mathrm{o}} 306,895,1068$ y 1216.

${ }^{8}$ Ibn al-Farađī, b. 1202, El nacimiento tuvo lugar en el primer tercio de la noche de una feria tercera (martes) 7 del mes de šawāl, del año 269 H., correspondiente al 19 de abril del 883.

${ }^{9} \mathrm{Cl}$. Addas, "Andalusī Mysticism and the Rise of Ibn flArabī", en S. Khadra Jayyusi (ed.), The Legacy of Muslim Spain, vol. II, pp. 913-914.

${ }^{10}$ M. Asín Palacios, op. cit., p. 41.
} 
Cuando falleció su padre, Ibn Masarra tenía diecisiete años. Siguiendo las escasas informaciones que apuntan sobre él los biógrafos ${ }^{11}$, le perdemos la pista desde el fallecimiento de su padre hasta el año 912 (300 H.), en los últimos años del emirato de flAbd Allāh. Las fuentes nos lo presentan viviendo en la cercanías de Córdoba, en la sierra12, rodeado de un círculo de discípulos a quienes guiaba bajo su magisterio espiritual. La mayoría de los autores que nos trasmiten su biografía acentúan su vida retirada "lejos del estruendo de la gran urbe"13 y presentan su dedicación de modo tendencioso. Dice Asín: “Adoctrinaba a los iniciados en el secreto esotérico"14. Y, dando la razón a sus detractores, describe Cruz Hernández:

Apareció en una ermita en la sierra de Córdoba, rodeado de un pequeño círculo de discípulos, que a simple vista eran un grupo más entre los ascetas que allí vivían una vida de oración y penitencia. Pero no hay duda de que Ibn Masarra enseñaba las doctrinas mufltazilíes, porque muy pronto fue acusado de sostener la doctrina del libre albedrío y de negar la realidad física de los castigos del Infierno; y un docto y celoso alfaquí cordobés, Ałmad b. Jalīl al-Habbāb, escribió un libro refutando sus errores. Esto obligó a Ibn Masarra a expatriarse, recorriendo el norte de África en compañía de sus fieles discípulos Muhammad el medinés e Ibn al-Şayqāl, marchando a Oriente, donde estudió las doctrinas mufltazilíes y sufíes, regresando a Córdoba durante el reinado de flAbd al-Rahmān III"15.

Generalizaciones semejantes podemos encontrar en diferentes autores actuales a la hora de tratar a Ibn Masarra. Me parecen simplificaciones acerca de nuestro autor que pueden resultar tergiversadoras y contradictorias con lo que reflejan sus textos. Por otro lado no he encontrado testimonio alguno que asegure que Ibn Masarra enseñase las doctrinas mufltazilíes y, sin embargo, es una afirmación que encuentro en distintos estudiosos, incluso con la siguiente

\footnotetext{
11 Al-Farađī, b. 1.202; al-Đabbī, b. 163; Ibn Jāqān, Matmah (ed. Constantinopla 1302 H.), p. 58; Maqqārī, ed. Leyden, II, 376. Se citan entre sus maestros andalusíes, además de su padre: Muhammad ibn Wađđāh y al-Jušanī (ambos jurisconsultos malikíes), a quienes ya nos hemos referido.

12 A este dato topográfico debe Ibn Masarra el sobrenombre de al-Ŷabali, que consta también en las biografías de algunos de sus discípulos: Takmila, bb. 339 y 113.

${ }^{13}$ M. Asín Palacios, loc. cit. p. 41.

14 Idem.

${ }^{15}$ M. Cruz Hernández, "El primer desarrollo del pensamiento andalusí: Ibn Masarra y su escuela”, en Historia del pensamiento en el mundo islámico, II, El pensamiento de al-Ándalus (siglos IX-XIV), Madrid, Alianza Editorial, 2000, p. 25.
} 
formulación: "Decíase que Ibn Masarra les enseñaba la herejía mufltazil que atribuye a la libertad humana la causalidad eficiente de todos sus actos" 16 .

A mi parecer hay una tendencia a exagerar las cuestiones más conflictivas y tratar con sensacionalismo las más efectistas con perjuicio para un análisis sobrio acerca del autor. La mayoría de comentarios de su vida y obra están sin documentar, y cuando se conoce la fuente, o bien se trata de biógrafos tardíos, o bien de detractores del autor y su pensamiento. Se deben evitar las generalizaciones y las afirmaciones categóricas que clasifican a nuestro autor y lo reducen a un tópico sin profundizar en su obra. Imaginemos por unos instantes que sólo conociésemos a Ibn flArabī y su obra a través de las críticas de Ibn Taymiyya $u$ otros detractores de su pensamiento.

No obstante, se aprecia un análisis muy sistemático y de una gran intuición en el estudio de Asín Palacios a pesar de su época, de sus circunstancias sociales y de su clara inclinación cristiana (más riguroso que el de otros estudiosos que tratan a Ibn Masarra sin haber examinado exhaustivamente las fuentes, eludiendo el claro perfil de maestro sufí que los textos nos evidencian). Se debe considerar que para Asín tratar a un autor musulmán ya era de por sí un asunto muy controvertido, por lo cual lo hace de una manera paradójica. Dos vertientes se debatían en el padre Asín: la pasión hacia lo que estudiaba y, en definitiva, un respeto profundo hacia el Islam, y a la par una cierta aversión hacia lo islámico, como bien refleja el primer párrafo que hemos anotado para conocer el prisma desde el que mira, intentando justificar su entrega al estudio de un autor islámico por medio de su "españolización". Para ubicar esta ideología podemos remitirnos a la Historia de los heterodoxos españoles de Menéndez Pelayo.

Acerca de su vida, aunque se ha especulado mucho, creo que es revelante apuntar, además de la relación con su padre y los maestros del entorno, que desde muy joven Ibn Masarra se presenta como destacado maestro en filosofía y en mística. Como trayectoria de su aprendizaje, emprendió viaje desde la serranía de Córdoba a Oriente, donde se relacionará bien en persona, bien por intermediarios, con los grades maestros sufíes de la época (Sarī al-Saqatī, Maflrūf al-Karjī, Sahl alTustarī, D̃ū 1-Nūn, etc.). Vuelve a la Península en el 912 continuando su enseñanza a modo de escuela, incluso podríamos decir a modo de zaríqa, con la práctica de la suћba, relación de compañía, inaugurando así en al-Andalus esta manera de organización de maestro y discípulos dentro de la vía iniciática de la mística

\footnotetext{
${ }^{16}$ M. Asín Palacios, loc. cit. p. 41.
} 
musulmana llamada susfismo ${ }^{17}$. Todo parece indicar que acabó sus días en paz en la sierra de Córdoba en el año 931.

Aunque la mayoría de los estudiosos de Ibn Masarra trasmiten de él que fue gravemente acusado de múltiples cuestiones (de batiní, de mufltazilí, de hereje, de panteísta, etc.), lo cual no considero tan relevante con relación a su obra conocida, ello nos sirve para explicar que no se hayan conservado de su obra escrita más que algunos fragmentos trasmitidos por algunos biógrafos como al-Qiftī, por detractores, o por místicos más tardíos (como Ibn flArabī, Ibn Qasī, Ibn al-flArīf, etc.). Tal vez las sospechas suscitadas por sus obras entre los medios ortodoxos han podido contribuir a la desaparición de sus escritos principales.

Además sabemos que su elaboración doctrinal y su influencia fueron considerables tanto en su entorno, como en la posterioridad, según podemos corroborar en Ibn flArabī o Ibn Hazm.

Explica Asín la dificultad de reconstruir el pensamiento de Ibn Masarra:

\begin{abstract}
El misterioso velo tras el cual Ibn Masarra ocultaba su doctrina, el sello esotérico de sus escritos, el reducido número de sus discípulos, la tacha de herejía e impiedad con que se vieron señalados, todo este conjunto de circunstancias explica suficientemente la penuria de medios con que hay que luchar hoy para reconstruir su sistema. Huelga decir que ni uno solo de sus libros se conserva. Es más: ni siquiera fragmentos de alguno de ellos han llegado hasta nosotros. Sólo, pues, por caminos indirectos cabe rastrear e inducir algo de lo que fueron sus ideas..$^{18}$
\end{abstract}

Se trata, pues, como vemos, de rastreo e inducción, pero no de crítica textual. La obra de Asín no permite conocer a Ibn Masarra en una realidad histórica y textual, sino únicamente abordar las polémicas suscitadas con respecto al autor entre los críticos.

Podemos pues definir dos momentos evidentes sobre los estudios acerca de Ibn Masarra, hablando de un antes y un después de Asín Palacios. Otros dos hitos que debemos señalar son el antes y el después del hallazgo de dos de sus obras, hallazgo que cambia enormemente el horizonte de la investigación, la cual ha de centrarse en los textos.

Durante largo tiempo se ha estudiado a Ibn Masarra sin haber encontrado ninguna de sus obras, aunque se habían trasmitido las referencias de los títulos. En el año 1972, Muћammad Kamāl Ibrāhīm Ŷaflfar daba noticia de su hallazgo en un

17 Dozy, en su Historie des musulmans d'Espagne, 2a ed., Leiden, 1932, II, pp. 127-28, hace una conexión directa entre la escuela masarrí y el sufismo andalusí que apareció más adelante.

${ }^{18}$ M. Asín Palacios, op. cit., p. 53. 
artículo $^{19}$ : había descubierto dos obras, hasta entonces consideradas perdidas, en la Chester Beatty Collection, cat., V. I (Arberry), ms., núm. 3168, de Dublín. En el 1978, Ŷaflfar edita las dos obras en un volumen ${ }^{20}$ que trataba de diversos aspectos

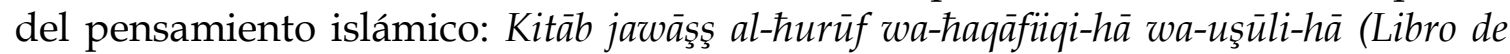
las propiedades de las letras, de sus verdaderas naturalezas y de sus principios) y Risālat al-ifltibār (Epistola de la reflexión).

Hasta ahora no existe ninguna traducción completa con edición crítica de

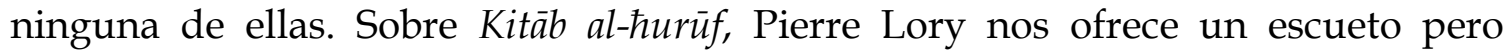
preciso y riguroso examen en el Dictionnaire critique de lfiésotérisme ${ }^{21}$. Por su parte, el profesor Emilio Tornero dio noticia al arabismo español del hallazgo de Ŷaflfar en un artículo ${ }^{22}$ donde nos expone un estudio de ambas obras con fragmentos muy breves traducidos. También he encontrado una traducción -esta sí, completa- de la Risālat al-ifltibār, realizada en inglés por Joseph Kenny ${ }^{23}$, la cual muestra una tendencia -a mi parecer excesiva- a interpretar "filosóficamente" al autor, sin reflejar el carácter místico sufí que a mi entender tiene su obra, en la cual se concilia la hermenéutica propiamente sufí con el pensamiento de vertiente filosófico-teológica. Sobre otro título de Ibn Masarra del que se tienen noticias, Tawhìd al-muqininn nada nos dice Ŷaflfar. Tenemos constancia también de otra obra llamada Kitāb al-tabŷīn ${ }^{24}$ que Šams al-Dīn al-Qurtubī nombra en su famosa Tadkìira que contiene el hadiz del Día del Juicio, que Ibn Masarra deriva, explicando directamente de sus principales maestros, su padre e Ibn Wađđāh.

Sobre su pensamiento y sobre su adscripción a las distintas corrientes, nos encontramos con la polémica de dónde clasificar y enraizar la doctrina de Ibn Masarra. En principio, la mayoría de estudiosos del autor coinciden en que su pensamiento es cercano al del filósofo griego Empédocles (siglo V a.C.) o, más concretamente, al de escritos pseudoempledocleanos cuya traducción árabe

${ }^{19}$ M. K., Ŷaflfar, "Min mufiallafāt Ibn Masarra al-mafqūda”, en Maŷallat Kulliyyat al-Tarbiya, Trípoli, 3-4, 1972-1974, pp. 27-63.

${ }^{20}$ M. K., Ŷaflfar, Min qađāyāa l-fikr al-islāmī: Dirāsa wa-nuşūş, El Cairo, Maktabat Dār al-flUlūm, 1978, pp. 310-360.

${ }^{21}$ P. Lory, "Ibn Masarra”, en J. Servier (ed.), Dictionnaire critique de lfiésotérisme, París, PUF, 1998, pp. 663-635.

22 E. Tornero, “Noticia sobre la publicación de obras inéditas de Ibn Masarra”, en Al-Qantara, XIV (1993), pp. 47-64.

${ }^{23}$ J. Kenny, "Ibn Masarra: his Risāla al-ifltibār", Revista Orita, 34, 2002, pp. 1-26.

24 Šams al-Dīn Qurtubī, Al-Tad'kīra fi aћwāl al-mawtā, Beirut, n. d., p. 341. Cf. Cl. Addas, op. cit. p. 914. 
circulaba entre los medios ilustrados. Pero no están de acuerdo a la hora de definir cuál es para cada uno la interpretación del pseudoempédocles ${ }^{25}$, ni en si influye a nuestro autor o lo determina. Hay una tendencia entre los arabistas a explicar el pensamiento de los místicos-filósofos andalusíes mediante el neoplatonismo, el pseudoempédocles, el aristotelismo, etc., que en el caso de Ibn Masarra se ve acentuada al haber una gran carestía de crítica intertextual. Personalmente, a la luz de sus obras, no concedo tanta importancia al hecho de que haya en su pensamiento reminiscencias del corpus pseudoempedocleano ${ }^{26}$. Lo que considero esencial es entender y reconocer el carácter profundamente islámico de la orientación filosófica y mística de Ibn Masarra.

En esta misma dirección, James W. Morris ${ }^{27}$ piensa que la mayoría de los orientalistas, incluyendo a Asín Palacios, han construido su idea de la figura y

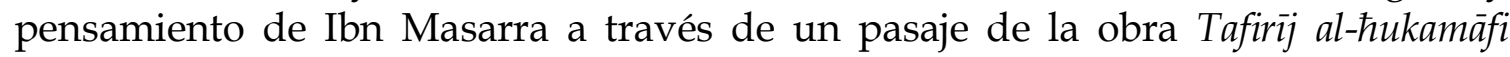
cuyo autor, al-Qiftī (m. 646/1248), vivió tres siglos después de Ibn Masarra y relaciona a nuestro autor directamente con los batiníes y a su vez, con los escritos neoplatónicos atribuidos por los árabes a Empédocles y a Pitágoras. Tenemos más ejemplos que nos explicita James Morris en esta línea de simplificaciones, o de grandes polémicas especulativas a partir de fuentes no pertinentes o pasajes escuetos, o de autores tardíos impregnados por su propia subjetividad, en ocasiones detractores. Dozy en su obra History of Muslim Spain justifica que Ibn Masarra sea considerado batiní, aduciendo que ejercía el papel de "emisario secreto de la propaganda fatimí en España"28, y todo ello a partir de una sola frase tomada de Şāflid ${ }^{29}$ (m. 462/1070). Goldziher lo trata como un "librepensador", nos lo presenta como mufltazilí y encauza desde la mufltazila el origen y desarrollo de lo que él llama escuela masarrí: "En el siglo XI el Islam español fue tempranamente penetrado por un movimiento ya latente de librepensadores que se vino llamando masarriyya" 30 . Dozy, con las mismas justificaciones hipotéticas, hace la conexión entre la escuela masarrí y el sufismo andalusí posterior. A raíz de estas

\footnotetext{
${ }^{25}$ Asín Palacios no remite a la versión de Šahrazūrī, Rawđa, (Manuscrito 1488, Leid.).

${ }^{26}$ Cf. "Ibn Masarra, gnóstico y místico andalusí", J. Solana (ed.), en Las raíces de la cultura europea. Ensayos en homenaje al profesor Joaquín Lomba, Zaragoza, Prensas Universitarias de ZaragozaInstitución Fernando el Católico, 2004, pp. 223-239.

27 Véase Cl. Addas, "Andalusī Mysticism and the Rise of Ibn flArabī”, p. 912, donde la autora menciona que se basa en el trabajo de Morris, J.W., A Reconsideration of the Primary Sources, escrito en 1973 (que no está publicado).

${ }^{28}$ Histoire des musulmans dfiEspagne, $2^{\mathrm{a}}$ ed., Leiden, 1932, II, pp. 127-128.

${ }^{29}$ Şāflid, Fabaqāt al-umam, en L. Cheiko (ed.), Beirut, 1912, pp. 20-21; Blachère (trad.), París, 1935.

30 Goldziher, Le livre dfilbn Toumert, Argel, 1903, pp. 66-69.
} 
consideraciones me gustaría dejar abierta la hipótesis de la trasmisión de la escuela de Ibn Masarra a los sufíes posteriores en al-Andalus para explorar sistemáticamente el posible influjo.

En cuanto a la mayor influencia del pseudoempédocles que del neoplatonismo, siendo ambas las corrientes que circulaban en la época, nos hace observar el profesor Pierre Lory que:

Ibn Masarra había elaborado una doctrina de la emanación situando como primera hipóstasis no el Intelecto universal y después el Alma universal -como en Plotino y los neoplatónicos musulmanes- sino una Materia primera (flunşur) inteligible, no sensible, coeterna con Dios, a partir de la cual, Dios habría hecho surgir todos los seres particulares. Asimismo, habría creído en la preexistencia de las almas dentro del Alma universal, su degradación en las formas materiales y su redención gracias, especialmente, a las enseñanzas de los profetas $^{31}$.

Tendríamos que adentrarnos en sus obras, como ha hecho Lory, para comenzar a alejarnos de las hipótesis y estudiar el legado que realmente nos trasmitió Ibn Masarra. En esta línea, si nos aproximamos a una de sus dos obras, titulada Libro de las propiedades de las letras, de sus realidades metafísicas y sus orígenes, observamos que es un tratado sobre el valor simbólico de las letras del alfabeto árabe que puede inscribirse en la tradición de textos de tipo sufí que aspiran a alcanzar un conocimiento de la realidad y de las más altas verdades a través de la interpretación de las letras. Estas especulaciones sobre el esoterismo de las letras nos conduce al centro del pensamiento masarrí en el cual la Materia primera del mundo parece ser consustancial a la Palabra Divina.

Como nos explica a través del estudio de la obra Pierre Lory, el Kitāb al-ћurūf no se presenta como un tratado filosófico. El propósito de la obra no es la argumentación por encadenamientos de razonamientos demostrativos, sino por las mediaciones e intuiciones derivadas de las analogías a partir de datos coránicos. Ibn Masarra nos previene de ello desde la introducción: “El Corán suministra a los hombres una ciencia unificada, desglosada en tres órdenes de saberes religiosos : 1/ La ciencia divina y sus percepciones contemplativas, 2/la ciencia profética, sus signos y alusiones, 3 / la ciencia probatoria que son los mandamientos legales y dogmas 32 ". El sentido de la enseñanza espiritual de Ibn Masarra es hacer pasar al discípulo del tercer estado de creyente ordinario al primero, el del perfecto místico. Consiste en conducir al lector del texto coránico a través del sentido esotérico del

$31 \mathrm{~V}$. nota 21.

32 P. Lory, op. cit, p. 663. 
Libro santo, transmutando la significación usual de los versículos para permitir que las exhortaciones usuales impacten en el alma del sufí, en lo más íntimo de su persona. Dice Ibn Masarra: "Cada letra luminosa es un signo divino, un atributo divino; aquel que se ha instruido en su conocimiento llega a aprehender un aspecto de la profecía". De entrada, el mismo Ibn Masarra subraya que "la ciencia esotérica del Corán es la comprensión de los nombres divinos expuestos por el Profeta"33. Compara los 99 nombres divinos enumerados por la tradición con los peldaños de una escalera tendida entre el creyente y el Paraíso. Cada nombre se divide asimismo en grados intermedios. La ascensión interior del iniciado de un grado, de un nombre a otro, se convierte así en referencia de su propio progreso espiritual. En la comprensión mística del nombre opera cada vez una transformación en el ser del espíritu. Empleando los términos de H. Corbin, el hombre se purifica en este proceso de lo humano y lo imperfecto para conformarse y unirse con la perfección divina en un proceso de "teomorfosis", que es el más elevado fin del proceso sufí. Se constata entonces que el papel del Corán sobrepasa con mucho el del simple mensaje exhortativo: esclarece el sentido oculto de las cosas y nombres para aquellos que lo saben escrutar. Por ello la comprensión del sentido de los versos coránicos es transformante: revela a nuestra conciencia lo que somos originalmente, ya que todos los seres celestes y terrestres son fundamentalmente entidades lingüísticas llamadas a ser leídas y descifradas. Recordemos que el Corán afirma que Dios ha creado el mundo por su palabra diciendo a cada cosa: “¡sé!" 34 , por tanto el mundo entero despliega y manifiesta el discurso divino.

Veamos ahora, para concluir, un ejemplo de la influencia que tuvo Ibn Masarra en el Šayj al-Akbar, Ibn flArabī, que fue más tarde el máximo exponente de la ciencia de las letras en el sufismo.

En el libro titulado Sobre el significado esotérico de las letras mìm (M), wāw (W) y

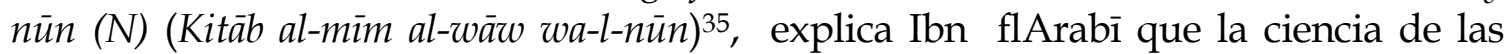
letras está reservada a los profetas y a los awliyāfi. Dice así:

Es esta ciencia de las letras una sublime estación que confiere los divinos conocimientos del Ser que corresponden a las contemplaciones (mašāhid) de la mìm, la wāw y la nūn, cuya

\footnotetext{
33 Idem.

34 Alusión a C. 2:117; 3:47 y 59; 6:73; 16:40; 19:35; 36:82; 40:68.

35 Próximamente aparecerá una primera edición crítica y traducción al español de este tratado que estoy realizando.
} 
primera letra en el nombre que las designa es igual a la última, de modo que no tienen principio ni final ${ }^{36}$.

Sabed pues -que Dios os conceda lograrlo-, que las letras son uno de los secretos de Dios -enaltecido sea- y que la ciencia de las letras es una de las más elevadas de entre las ciencias guardadas en los tesoros de Dios ${ }^{37}$. Es parte de la ciencia preservada con la cual se distingue a los profetas (anbiyāfi) y a los allegados (awliyāfi) que tienen corazones puros. De ella dijo al-Hakīm al-Tirmidì que es la ciencia de los santos amigos (flilm al-awliyāfi)".

Tirmidī, autor entre otras obras del Libro de la profundidad de las cosas 38 , que puede leerse en francés, aparece aquí como eminente representante de esta ciencia que distingue a los amigos de Dios. Ibn flArabī, evocando al gran sufí oriental, sugiere que la ciencia de las letras es la ciencia de los awliyäfi por excelencia.

Más adelante, en esta misma obra, explica Ibn cArabī que su discurso versa sobre los misterios de las letras y no sobre sus propiedades simpatéticas (jawāşş) y cita, precisamente, a título de ejemplo, el estilo de Ibn Masarra. Dice así:

Nuestro discurso versa sobre sus secretos [los de las letras de la lengua árabe] -en lo cual seguimos un proceder ( tarīqa) semejante al de Ibn Masarra al-Ŷabalī y otros maestros, no sobre sus propiedades simpatéticas (jawāşş), pues el discurso acerca de las utilidades de las cosas induce a que se sospeche (tuhma) del autor y a que se le desmienta [y se le tenga por impostor] (takdîb) en la mayoría de los casos.

Esta mención de Ibn Masarra resulta muy reveladora. En primer lugar, como en otras referencias de Futū̄āt makkiyya, Ibn flArabī manifiesta conocer a Ibn Masarra, en particular, por su Tratado de las letras, tal vez leído por el autor o acaso sólo transmitido a él de forma oral. Es interesante notar que son los sufíes y no los filósofos quienes recuperan la figura de Ibn Masarra y reivindican una ascendencia masarrí.

36 Ya que la identidad de comienzo y fin establece un principio de circularidad. En su edición provisional, Gillis lee šăhid en lugar de mašăhid (v. Ibn flArabī, Le Livre du Mìm, du Wā̃w et du Nūn, París, Albouraq, 2002, p. 38).

${ }^{37}$ Alusión a C. 15:20.

38 V. Al-Hakīm, Tirmid'i, en G. Gobillot (ed. y trad.), Le livre de la profondeur des choses, Villeneuve d'Ascq (Nord), Presses Universitaires du Septentrion, 1996. 
Por otra parte, el hecho de mencionar a Ibn Masarra -como antes a Tirmidî̀con relación a la ciencia de los awliyāfi por excelencia, revela un profundo reconocimiento de su condición de wali, amigo de Dios $\mathrm{y}$, por ende, maestro espiritual. Ibn flArabī manifiesta además una intensa vinculación al pensamiento masarrí cuando afirma que sigue en el tratamiento de esta ciencia privilegiada una vía "como la vía" de Ibn Masarra (ka-tarīqa Ibn Masarra). Entendemos que esta analogía de método se refiere al hecho de que ambos maestros tratan de las letras desde una doble perspectiva metafísica y simbólica con un mismo trasfondo escriturario. No se trata pues de dar a conocer las propiedades o virtudes operativas de las letras -dominio propio de la medicina simpatética o la magia-, sino de ahondar en sus significados y realidades espirituales en un contexto netamente alcoránico.

Lo que resulta llamativo es que el título que del tratado de Ibn Masarra sobre las letras aparece en el manuscrito conservado $y$ se ha transmitido

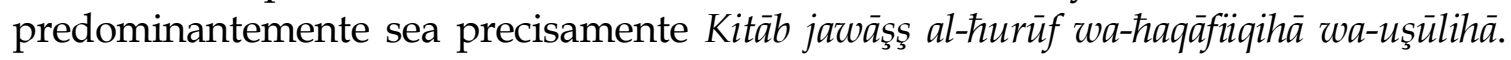

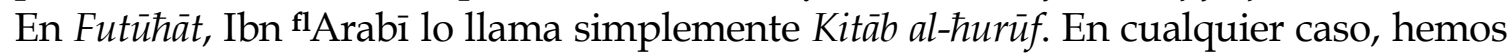
de entender que el término jawāşş, si fue empleado por Ibn Masarra en el título, designa aquí las cualidades o características de las letras y no sus virtudes operativas. 